\title{
Salve-te, Strela do mar: himnodia y mariología en las Cantigas de Santa María de Alfonso X el Sabio ${ }^{1}$
}

\author{
Salve-te, Strela do mar: hymnody and mariology in Alfonso X's Cantigas de Santa \\ María
}

\author{
Santiago Disalvo \\ santiago.disalvo@gmail.com \\ Universidad Nacional de La Plata. Facultad de \\ Humanidades y Ciencias de la Educación. Instituto de \\ Investigaciones en Humanidades y Ciencias Sociales. \\ CONICET, Argentina
}

Recepción: 23 Abril 2021

Aprobación: 28 Julio 2021

Publicación: 01 Noviembre 2021

Cita sugerida: Disalvo, S. (2021). Salve-te, Strela do mar: himnodia y mariología en las Cantigas de Santa María de Alfonso X el Sabio. Olivar, 21(34), e106. https://doi.org/10.24215/18524478e106

\begin{abstract}
Resumen: Además de los miracula marianos de tradición clerical latina, otro tipo de literatura está entretejido en los versos de las Cantigas de Santa Maria, de Alfonso X el Sabio. Si bien son producto de una novedosa creatividad poética en romance, estos textos dejan oír claramente las voces de un universo doctrinal teológico y mariológico y, especialmente, los ecos de la himnodia litúrgica. Como demostración de este fenómeno, se estudian la cantiga de loor 180 y la cantiga narrativa 288 .
\end{abstract}

Palabras clave: Alfonso X, Cantigas de Santa María, Himnodia, Fuentes, Mariología.

\begin{abstract}
In addition to the Marian miracula of latin clerical tradition, another type of literature is woven into the verses of Alfonso X's Cantigas of Santa Maria. Although these texts are the product of a new poetic creativity in Romance language, they clearly show the voices of a theological and mariological doctrinal universe and, especially, the echoes of liturgical hymnody. As a demonstration of this phenomenon, two poems are studied, cantiga de loor 180 and narrative cantiga 288.
\end{abstract}

Keywords: Alfonso X, Cantigas de Santa Maria, Hymnody, Sources, Mariology.

En 1983, el himnólogo Joseph Szövérffy explicaba la himnodia litúrgica latina como "a poetic Atlantis, a literary world of depth and magnitude unequalled in many periods of Western cultural development, separated from us by language and spirit and still a part of a common Western heritage" (Szövérffy, 1983, p. vi). El universo de los himnos litúrgicos, una de las manifestaciones líricas más importantes de los siglos medievales, influye de modo muy variado en el resto de la literatura religiosa tanto latina como románica. Entre los géneros poéticos que forman parte de la liturgia están, en primer lugar, los ciento cincuenta salmos bíblicos, además de diversas oraciones, antífonas, preces, responsorios, pero también los cánticos, tanto los veterotestamentarios como los llamados “cánticos evangélicos”, es decir, el Benedictus, el Magnificat y el Nunc dimittis. En los primeros tiempos de la evolución del culto cristiano, se había empezado a destacar el himno, bymnus, que terminó ocupando un lugar especial por ser el género litúrgico más librado a la creatividad 
poética. ${ }^{2}$ La himnodia medieval occidental, de enorme vastedad y riqueza, está contenida generalmente en colecciones de piezas anónimas, hymnarii, que han de ser insertadas en la liturgia, eventualmente, como canto inicial en las horas canónicas, variando según las fechas de ferias, domingos, solemnidades, fiestas y memorias de santos, de acuerdo con los tiempos del año litúrgico. A la himnodia strictosensu se suman las antífonas y los tropos y, como categoría especial, las sequentiae cum prosa (o prosae, recogidas en prosaria), más tardíamente denominadas por analogía como los "himnos" propios de la misa, insertos entre la epístola y el evangelio. Las series de imágenes, figuras y tópicos marianos que pueblan los textos, los diversos subgéneros líricos específicos (gaudia, planctus, himnos de septem doloribus, sequentiae y antífonas), y una entera materia narrativa propia, los milagros (miracula), compilados en colecciones y configurados en subtipos y "ciclos", conforman un verdadero "sistema mariano" que puede plasmarse tanto en prosa como en verso narrativo, lírico, dramático, tanto en la palabra, con su correlato musical, como en las artes plásticas. Al inicio es la liturgia la que, sobre todo en sus partes más literariamente fecundas como la himnodia, abona este crecimiento que fructifica en Occidente de a poco, aunque mucho antes de los siglos del esplendor mariano, el XII y el XIII. No es sorprendente entonces que, durante los siglos centrales de la Edad Media, las formas provenientes de la tradición litúrgica se encuentren entretejidas en los textos de los milagros marianos, sea como cita, las más de las veces, sea como discurso directo de uno de los personajes del relato. En algunos casos, el asunto mismo del milagro gravita en torno a la ejecución o a la "creación" de un canto litúrgico. Aunque se trata en su mayor parte de cantos conocidos de la tradición litúrgica anónima, es posible vislumbrar en algunos casos el sustrato de un himno o secuencia atribuible a un autor particular. Por otro lado, esta sugestiva interrelación entre la himnodia y la materia narrativa de los milagros implica una influencia en sentido contrario, es decir, cuando la narrativa miracular parece irrumpir en los textos de la himnodia litúrgica latina. Una clara muestra es la pieza mencionada por Fidel Fita, tomada de un Diurnal de Córdoba del siglo XIV, que recuerda al clérigo sumergido salvado por la Virgen:

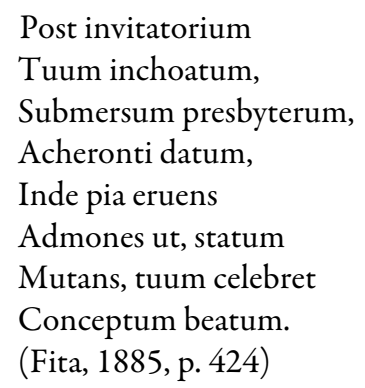

Podrían aducirse muchos otros ejemplos, como las siguientes estrofas de algunos Gaudia de manuscritos ingleses de los siglos XIII y XIV (Cod. Londinen. Arundel. 243) que aluden a los milagros marianos de Teófilo (correspondiente a la cantiga 3) y de Basilio de Cesarea (cantiga 15, ms. T 5):

Tu Theophilum pie,

Inferis abstractum

Reformasti gratiae,

Irritasti pactum,

Auctorem malitiae

Inter et ipsum factum,

Reddens sub spe veniae

Chirographum actum.

Tu tuum Basilium

Attendens rogantem

Per quendam Mercurium

Tibi militantem

Julianum impium, 
Apostatam regnantem,

Te tuumque filium

Perdis blasphemantem.

(185. De XV Gaudiis BVM; Blume y Dreves, 1898, p. 191)

Es menester contextualizar la lírica y la narrativa hispánica mariana dentro de este "gran sistema" europeo, considerando los diversos modos de traducción y reelaboración de la himnodia litúrgica y los textos doctrinales, de la mariología y los tópoi marianos altomedievales y sus cambios en la etapa floreciente del culto mariano occidental en los siglos XII y XIII. La himnodia latina no conoce fronteras nacionales y, en ámbito hispánico, es constatable el influjo de Francia y particularmente de las escuelas parisinas. Pero la línea amplia de influencias puede abarcar desde las oraciones e himnos de los siglos VIII a X y su herencia tardoantigua, la influencia de los mariólogos tempranos como Ildefonso de Toledo, Ambrosio Autperto, Beda el Venerable (cfr. Gambero, 2000) y de la liturgia visigótico-mozárabe, hasta la himnodia transpirenaica e insular y diversos autores del siglo XII como Adán de San Víctor y San Bernardo de Claraval. La himnodia ibérica en latín está constituida por ricas colecciones anónimas y algunos autores bajomedievales. Solo para ejemplificar someramente, podemos destacar el Codex Calixtinus con sus piezas de canto litúrgico, himnarios como el Oscense, el Matritense, el Illerdense, el Corpus rhythmorum contenido en el códice Alcobacense 149, los himnos del Officium Parvum de fray Juan Gil de Zamora en su Liber Mariae, los cantos del Llibre Vermell de Montserrat y la gran colección himnódica consituida por el Códice de Las Huelgas, manuscrito, editado y descripto en diversas ocasiones (Anglès, 1931; Asensio Palacios y Lorenzo Arribas, 2001; Bell, 2004), entre otros.

Ahora bien, siendo la himnodia litúrgica una de las vertientes más importantes de la poesía creativa propia del ámbito monástico, su influencia se percibe como un aspecto de la representación del monacato en las Cantigas de Santa María. La cultura monacal, como hemos tenido oportunidad de describir (Disalvo, 2013b) es indudablemente una gran fuente y un modelo para la creación de las Cantigas de Santa María. La materia mariana es de diversa índole, desde relatos miraculares de tradición monacal hasta piezas himnódicas que se citan o se imitan poética y musicalmente, sin dejar de considerar las fuentes doctrinales, es decir, conceptos mariológicos, por lo general de origen monástico, empleados sobre todo en las cantigas de loor y en los proemios de las cantigas narrativas. Más allá de los himnos explícitamente citados, se perciben otros modos de inserción de la lírica himnódica en la narración de los milagros. Es interesante intentar iluminar estos loci donde parece haber un texto apenas mencionado, casi encubierto, para considerar las modalidades de adopción de estos himnos y textos afines en las Cantigas de Santa María de Alfonso X. Algo similar ocurre, aunque menos rica y sutilmente, en los Milagros de Nuestra Señora de Gonzalo de Berceo, siendo ambas conocidas colecciones ibéricas de milagros marianos en verso del siglo XIII, aunque muy disímiles en su forma y extensión.

Las cantigas narrativas abundan en momentos de plegaria por parte de sus personajes y, por lo tanto, en ocasiones de canto individual o colectivo. Por ejemplo, en la cantiga 69 se entona una antífona en agradecimiento a la Virgen, en la 187 los monjes cantan "ynos e cantigos todos a mui gran perfia" (v. 27) y "salmos muitos e pois ledaŷas [letanías]" (v.34) en la 347. La cantiga 202 narra que un monje componía una "prosa", es decir, una sequentia cum prosa, y recibe una ayuda celestial para completar un verso de su poema. Algunos hechos relatados en las cantigas 32,73, 149, 222, 225, entre muchas otras, enmarcan el milagro en la celebración eucarística, aunque sin mencionar sus textos, mientras que las siguientes cantigas citan explícitamente los versos en latín de los himnos y antífonas cantados con ocasión del rezo de la liturgia de las horas, aunque en algunas oportunidades también como canto individual o alabanza espontánea:

cantiga 6: Gaude Virgo Maria

cantiga 11: Ave Maria

cantiga 16: Ave Maria

cantiga 42: Ave Maria 
cantiga 55: Salve Regina

cantiga 56: Magnificat + cuatro salmos

cantiga 71: Ave Maria

cantiga 93: Ave Maria

cantiga 121: Ave Maria

cantiga 125: Ave Maria

cantiga 141: Ave Maria

cantiga 151: Ave Maria

cantiga 152: Ave Maria

cantiga 180: Ave Maris Stella

cantiga 202: verso "Nobile triclinium" de Salve Mater Salvatoris de Adán de San Víctor

cantiga 210: Ave Maria

cantiga 253: Salve Regina

cantiga 262: Salve Regina

cantiga 270: Ave Maria (literalmente, “Ave gracia plena”)

cantiga 313: Salve Regina

cantiga 330: Ave Maria

No literal ni explícitamente, aunque sí de manera más vaga, pueden considerarse "fuentes primigenias" básicas para las Cantigas de Santa María, además de los mencionados Ave Maria, Salve Regina, Ave Maris Stella y Magnificat, otras antífonas e himnos de uso generalizado tales como el Alma Redemptoris Mater, el Ave Regina Caelorum, las letanías y otras piezas himnódicas. Así, pues, mientras el estribillo de la cantiga 40, "Deus te salve, groriosa, / Reya Maria, / lume dos santos fremosa, / e dos ceos via" (vv. 3-6), parece traducir libremente el Ave Maria y el Salve Regina, la cantiga 94 concluye con los versos "Salve-te, Strela do Mar, I Deus, lume do dia" (vv. 125-126), que parecen ser también traducción libre de versos del Ave Maris Stella con el agregado de alguna antífona como Deus lux viventium lumine (Cantus 201196). De la misma manera, es evidente que expresiones como Virga de Jesse ("rama de Jesé") en las cantigas 20 y 31, y Sola fusti ("Sola fuiste") en la 90, se remontan a textos de tradición litúrgica, cualesquiera hayan sido, del tipo de las antífonas del tiempo de Adviento "Virga de Iesse" (Cantus 830339), o de la secuencia "Virga Iesse floruit" (Wellner, 1955, p. 35), en el primer caso, y de las antífonas de la fiesta de la Asunción "Sola fuit mulier paruit" (Cantus 007270a), o bien "Gaude Maria virgo cunctas haereses sola interemisti quae Gabrielis archangeli dictis credidisti dum virgo deum et hominem genuisti et post partum virgo inviolata permansisti alleluia" (Cantus 002925), en el segundo. Por su parte, pueden considerarse "fuentes primigenias" las imágenes himnódicas del hortus mariano (Disalvo, 2010), la tradición de los septem dolores (Disalvo 2012b) y los gaudia (Disalvo, 2013c), así como los ecos de Adán de San Víctor (Disalvo, 2012a) y la relación de filiación de la cantiga III de las Festas de Santa Maria (413, ed. Mettmann, 1989) con piezas del Códice de las Huelgas burgalés (Rossi y Disalvo, 2008; Disalvo, 2013a). En este mismo sentido, la observación del extraño "comportamiento métrico" de la cantiga XI de las Festas de Santa Maria (421, ed. Mettmann, 1989), que suscitó en su momento la perplejidad de Dorothy C. Clarke (1955) y la sucinta nota de Philip Vandrey (1977) que remite a las referencias musicológicas de Higini Anglès (1958), no puede sino desembocar en la consideración de la herencia formal del canto y la poesía monástica en el cancionero alfonsí. Así, la cantiga XI de las Festas de Santa Maria parece constituir un raro caso de tropo litúrgico en romance, derivado del Códice de Las Huelgas y de manera muy similar ocurre con la cantiga 330, asimilable en tópicos, retórica y métrica a las secuencias victorinas y a las del Códice de Las Huelgas, excepto por la presencia del estribillo. También hemos visto que la cantiga III de las Festas recuerda, en poesía y música, al himno 56 de Las Huelgas (Rossi y Disalvo, 2008).

En último lugar, podría identificarse un tercer nivel "entre la música y el silencio", dado por una especie de cita implícita de versos de ciertos himnos litúrgicos en las Cantigas de Santa María, aspecto que hemos esbozado sucintamente en nuestro estudio de 2014 al tratar de la translatio de la materia mariana en el 
cancionero alfonsí. En ciertas cantigas, como la 288, que trataremos más abajo, en la 361 y en la 404 (ed. Mettmann, n. 76 del ms. To) que parece trasladar el himno Quem terra, pontus, ethera de Venancio Fortunato (Disalvo, 2013b y 2014), el uso del discurso directo señala, en cada caso, la presencia de lo que podemos llamar "himnodia escondida", es decir, citas de versos de himnos que no se muestran explícitamente como tales.

Tal como la espiritualidad cisterciense, cuyos nexos con las Cantigas de Santa María y el universo alfonsí son múltiples y relevantes, pudo echar mano de la contrafactura y la tipología como procedimientos poéticos para la creación de nuevos himnos, así el taller de Alfonso X empleó esos mismos procedimientos al momento de elaborar las piezas musicales, narrativas y líricas que se incluirían en las Cantigas de Santa María:

contrafactura was a means to gloss earlier compositions. For example, the family of Victorine sequences based on the antiphon Ave Maris Stella had a complex set of relations with the original composition. They commented first on the melody of the original antiphon, weaving it in and out of new melodic formulas. Furthermore, they glossed the original texts with new language, enriching its meaning. (...) Typology was another technical device that affixed new Marian verse to legitimate tradition. This technique, widely used in biblical analysis, became by the twelfth century a fixture of hymn composition as well. (Noell, 1999. pp. 47-48)

Focalizaremos el estudio en dos cantigas paradigmáticas por tratarse de poemas que condensan, por un lado, citas, menciones explícitas a poemas litúrgicos, a pasajes de textos bíblicos, a su secular lectura mariológica y, por otro, alusiones solapadas a himnos y sus autores, a su tradición literaria. En primer lugar, analizaremos la cantiga de loor $180 \mathrm{y}$, en segundo, la cantiga narrativa 288.

El Ave Maris Stella (Cantus 008272; Blume y Dreves, 1889 pp. 39-40, n. 29), un himno fundamental de la himnodia litúrgica occidental dedicada a la Virgen, está citado de forma explícita en la cantiga de loor 180. Se puede observar en el siguiente cuadro cómo la cantiga parece estar construida con ecos muy sutiles de los conceptos y tituli marianos presentes en el célebre himno: 


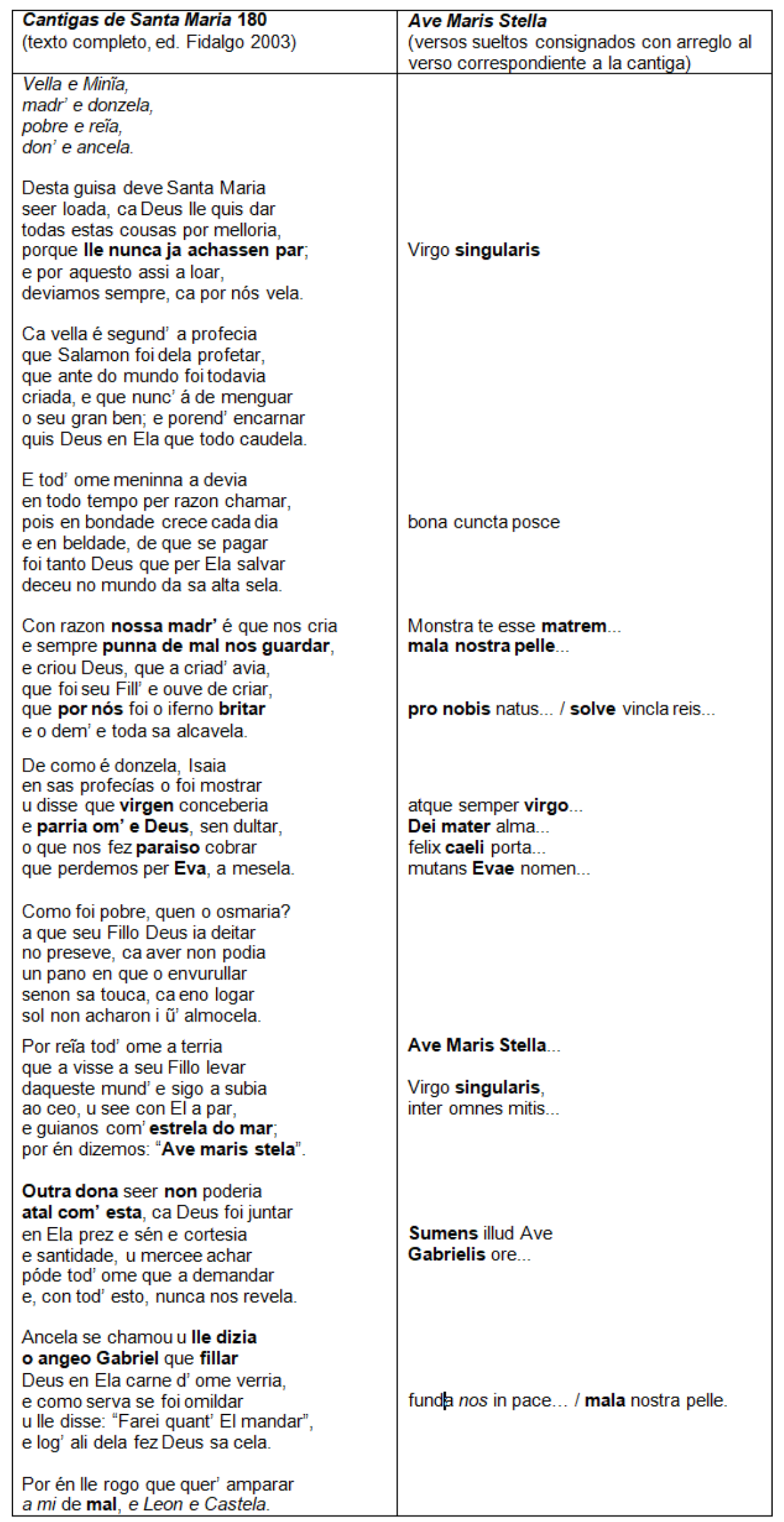


No puede dejar de sorprendernos que el patrón de coblas unissonans utilizado en las estrofas de esta cantiga remata en la rima -ela, lo cual es indicio de que toda la pieza pudo haber sido compuesta sobre el sintagma "Ave maris stel[l]a" que, siguiendo el esquema del "zéjel"-virelai, rima a su vez con palabras muy significativas del estribillo, donzela y ancela.

Según la expresión utilizada en el estribillo de la cantiga 180, la Virgen es al mismo tiempo "Vella e Minía", posterior a Dios por ser su criatura y anterior acaso por ser su madre. Pero el adjetivo vella, junto con el desarrollo que de este concepto realiza la primera estrofa de la cantiga 180, apunta evidentemente a otro problema doctrinal. Walter Mettmann (1979, p. 305), al listar todos los epítetos y advocaciones de la Virgen, advierte que, aunque sí existe en las mismas Cantigas de Santa María una expresión equivalente aplicada a Cristo ("o vell' e menĩo"), no ha podido encontrar en las fuentes un antecedente que corresponda de forma directa a "vella e menia". La segunda de las estrofas, que son una glosa o desarrollo de cada uno de estos conceptos, contiene la siguiente afirmación: "que ante do mundo foi todavia / criada, e que nunc' á de minguar / o seu gran ben; e porend' encarnar" (Mettmann, 1988, p. 193-194). Por un lado, la cuestión remite a la difusión el tópos del puer senex que Curtius ha utilizado para ejemplificar la importancia de la tópica de la literatura clásica y tardoantigua trasvasados a la medieval:

el motivo del rejuvenecimiento, que pertenece evidentemente a la misma esfera anímica del dualismo juventud-vejez que aparece en el tema puer senex. Lo encontramos por vez primera en la literatura apocalíptica del primitivo cristianismo. En el Pastor de Hermas (mediados del siglo II) se relatan visiones en las cuales la "Iglesia" aparece como anciana que se va rejuveneciendo poco a poco. Este texto se divulgó desde el siglo II en su traducción latina. Merece señalarse que aquí la "Iglesia" es además "el Espíritu Santo preexistente", representado ahora en figura femenina. (Curtius, 1955, p. 156)

Tanto Walter Mettmann (1988, p. 193, nota a vv. 13-16), en una nota a su edición, como Elvira Fidalgo suponen que el estribillo de la cantiga 180 remite al Salmo 109, v. 3:

A vellez atribuída á Virxe podemos entendela dende dúas perspectivas; por unha banda connota sabedoría, que na Virxe se pode entender de diferentes maneiras (beatífica, ciencia infusa e adquirida) e, por outra banda, alude inequivocamente á súa preexistencia lévanos ao Salmo 109, no que o autor - evidentemente apócrifo - di "Tecum principium in die virtutis tuae, / in splendoribus Sanctorum; / ex utero ante luciferum genui te". (Fidalgo, 2003 pp. 216-217)

Sin embargo, puede suponerse que esta imagen de María ante constitutionem mundi de la cual, según la cantiga, Salomón profetizó, proviene en realidad de los libros sapienciales entre los cuales es necesario destacar el Libro de la Sabiduría del Antiguo Testamento. En efecto, las reflexiones de este libro sapiencial, puestas en boca del rey Salomón, incluyen la siguiente invocación:

\begin{abstract}
Deus parentum et Domine misericordiae tuae qui fecisti omnia verbo tuo et sapientia tua constituisti hominem ut dominetur creaturae quae a te facta est ut disponat orbem terrarum in aequitate et iustitia et in directione cordis iudicium /iudicet da mibi sedium tuarum adsistricem sapientiam et noli me reprobare a pueris tuis

... et tecum sapientia quae novit opera tua quae et adfuit tunc cum orbem terrarum / faceres et sciebat quid placitum esset oculis tuis et quid directum in praeceptis tuis.
\end{abstract}

(Sap. 9, vv. 1-4, 9)

Se trata de la eterna Sapientia, venerada en la Iglesia oriental como la Santa Sabiduría, figura de Jesucristo, aunque aquí ciertamente considerada como una imagen de la Virgen antes de la creación, ya formada como idea en el seno del Padre. La cantiga 180 es mencionada por Leslie Twomey como "earliest vernacular application of Wisdom literature to the Virgin Mary" (2008, pp. 176-177). Justamente en el ámbito español, esto ha adquirido un especial relieve puesto que, como lo ha señalado la misma Twomey (2008, p. 176), se introduce el texto bíblico del Libro de los Proverbios $(8,23)$ en la liturgia en honor a Santa María donde se presenta la imagen femenina de la Sabiduría: "Because Proverbs is used so consistently in Castile as the capitulum at Conception vespers it is to be expected that many Castilian poets will give it pride of place in 
their poetic representations of the Conception" (Twomey, 2008, p. 178). Otros pasajes de libros sapienciales del Antiguo Testamento han sido interpretados como prefiguración de la Virgen María. Así, por ejemplo, en la liturgia de la Virgen del Pilar han sido introducidos los siguientes versículos del Libro del Eclesiástico, que celebran la creación de María antes de todos los tiempos:

Lectio Libri Eccli. (XXIV, 14-16). Ab initio, et ante saecula creata sum, et usque ad futurum saeculum non desinam et in habitatione sancta coram ipso ministravi. Et sic in Sion firmata sum et in civitate sanctificata similiter requievi et in Hierusalem potestas mea. Et radicavi in populo honorificato et in parte Dei mei hereditas illius et in plenitudine sanctorum detentio mea.

Entre los siglos XI y XII, se desarrollan algunos conceptos a partir de la mariología de siglos anteriores que confluirán en el tópico de la Virgen ab initio creata. Tal como explica el estudio de Francesco Santi (2004), un giro cosmológico parece haber influido en la mariología del siglo XI, cuando se buscó asimilar a la Virgen María con un espacio celeste. Atraía a los teólogos aquel caelum caeli (salmo 67) o caelum caelorum (salmo 113), entendido como la beata habitación de Dios fuera del tiempo, sobre todo desde las indagaciones de San Agustín (Confessiones, XII. 2), y que fue identificado con la Santa Sabiduría. Así, pues, la interpretación de ciertos pasajes bíblicos como profecías correspondientes a la Virgen en calidad de un ser ante saeculum y de caelo se desarrollaron en tanto aspectos de una cosmología teológica. San Bernardo interpretó esto como la dimensión mística de la Iglesia, pero autores anteriores, como San Pedro Damián, habían usado ya la imagen para referirse a la Virgen María, "el hermoso palacio celeste del rey, sostenido por las siete columnas de la sabiduría (sophiae)":

Aula caelestis speciosa regis

Fulta septenis sophiae columnis,

Quem nequit totus cohibere mundus,

Claudis in aluo.

(In Assumptione BMV.Ad Vesperas; Blume y Dreves, 1905, p. 32)

Y también,

Maria, decus hominum,

Regis aeterni solium,

Septem columnis edita

Domus a sapientia.

(De Beata Maria V. Ad Tertiam. Blume y Dreves, 1905, p. 35)

Este mismo autor, en un sermón dedicado a la Natividad, explica que la Virgen contiene en sí misma aquello que no puede ser contenido, el Creador y el orden actual del universo, encerrando así también la totalidad del tiempo. María es, por lo tanto, la pariens parientis y el origo principii. Aquí puede reconocerse la paradoja de lo infinito encerrado en lo finito, tópico presente también en las Cantigas de Santa María, heredado de la himnodia. Otro autor medieval, Ruperto de Deutz, señala a la Virgen como la Puerta celestial reservada solamente al Dios de Israel en la profecía de Ezequiel, asimilándola al cielo de donde baja el pan vivo y a la auténtica realeza celestial, elegida desde el inicio de la Creación:

Ruperto fu uno di quegli autori che apertamente proclamarono la regalità della Madre del Signore. Parlando della grandezza assolutamente unica di Maria, egli ne vide la radice e la spiegazione in quell' atto singolare di elezione con cui Dio l'ha scelta fin dall'inizio della creazione, applicando a lei le parole della Scrittura: "Il Signore mi ha creato fin dall'inizio delle sue opere... Dall' eternità sono stata costituita” (Pro 8, 22-23). (Gambero, 2000, p. 150)

Según la doctrina mariológica de estos teólogos, el Creador estableció el mundo en el tiempo a través del "cielo de los cielos", creado por Él fuera del tiempo. La Virgen María es este "cielo superior”, el caelum caeli de raíz agustiniana, "pre-creada", ante constitutionem mundi. Como todo hombre en la cosmovisión medieval, María es microcosmos, pero con la prerrogativa de representar la realidad cosmológica que antecedió al 
mundo caído por el pecado, es decir, el mundo carnal, pero en su forma no corrompida. El Verbo, circundado del esplendor del caelum caeli, emergió de ella como el nuevo microcosmos, Cristo.

La dudosa ortodoxia de este vínculo entre mariología y cosmología (que Alain de Lille señalaría como herético hacia el final del siglo XII) no ha impedido que se haya trasvasado sin límite aparente en la poesía desde entonces, ya que progresivamente sería leído a partir de la doctrina de la "pre-elección” o predestinación de la Virgen y, sobre todo, ampliamente utilizada en la poética mariana. El tópico gozará de larga vida, ya que, tras haber atravesado todo el siglo XV, entrará profundamente en la lírica del Renacimiento y del Barroco. Lo encontraremos en muchísimos poetas, desde Lope de Úbeda y el carmelita Pedro de Padilla hasta Cervantes y Sor Juana Inés de la Cruz, frecuentemente con el sentido de predestinación, pero muchas veces también con los matices propios de la "pre-creación"

El término "Marian poetics" ha sido empleado por autores como Georgiana Donavin (2012, pp. 66-68), retomando estudios anteriores de McDevitt y Rubin, para referirse a la influencia mariana en las artes y poéticas medievales, especialmente en el caso de la literatura inglesa: las figuraciones de María como Lady Rhetorica,magistra para los estudios de lenguaje, musa para la poesía y modelo perfeccionado de la grámatica y el habla (Donavin, 2012 y 2019). Es en esta perspectiva que hemos de considerar una magna obra como las Cantigas de Santa María, ya que la mariología, al menos durante la Edad Media, no puede considerarse una mera rama de la teología o un conjunto de doctrinas aplicadas a la especulación y a la catequesis, sino también una verdadera poética.

\section{II}

Dos cantigas narrativas se han derivado claramente de algunas redacciones de la vida de un santo inglés, San Dunstan de Canterbury, a saber las cantigas 288, Como un ome bõo de relijon foy veer a ygreja u jazia o corpo de Sant' Agostin, e viu y de noite Santa Maria e grandes coros d'angeos que cantavan ant' ela, y 296, Como Santa Maria apareçeu a un monje na çibdade de Conturbel e mostrou-lle como a servisse. 3 Estos poemas son partes procedentes de la misma historia original, de acuerdo con la mayoría de las fuentes y las más antiguas: la narración comenzó a dividirse en dos diferentes relatos de milagros, como podemos ver en las colecciones conservadas del siglo XII, como muestran los manuscritos Pez (Crane, 1925) y Alcobacense (Nascimento, 1979). Es posible agregarlas dentro de las "cantigas de milagros ingleses" (las cantigas 6, 23, 35, 36, 82, 288 y 296) o incluso un grupo más pequeño de "milagros de Canterbury" (cantigas, 82, 288 y 296), pero también, lo que es más interesante, dentro del grupo de cantigas que narran la "performance celestial” de ciertos himnos célebres.

En efecto, como señalamos inicialmente, varias cantigas relatan los orígenes celestiales de algunos poemas de la tradición litúrgica: Salve Regina, Ave Maris Stella, Salve Mater Salvatoris. Por ejemplo, la cantiga 262 cuenta una prodigiosa sanación obrada por la Virgen María en Le Puy en Vélay (Francia). Una mujer sordomuda, habiéndose quedado encerrada en una iglesia, oye un coro de santos que canta en honor de María la antífona Salve Regina. El texto aclara que "esta foi a primeira // vez que nunca foi cantada" (cantiga 262, vv. 23-25; Mettmann, 1989, p. 13). La antífona mariana Salve Regina de autoría incierta, fue utilizada como canto procesional en los monasterios cluniacenses y cistercienses, más tarde por los franciscanos y dominicos, y añadida a la hora de completas como oración final. La cantiga parece tener en cuenta la larga y célebre tradición de esta antífona en la cristiandad occidental, y narra la leyenda de su origen sobrenatural.

En las primeras fuentes de la visión San Dunstan, se introduce un himno del antiguo poeta cristiano romano Celio Sedulio (siglo V), con el añadido de algunos versos citados en el texto de Osbern. Pero en versiones posteriores, el nombre del poeta desaparece. En la cantiga 288, es posible reconocer el himno de Celio Sedulio solo si lo comparamos con los versos citados en las fuentes latinas anteriores. Sin mencionar a su autor, estos versos son reescritos como el discurso directo de voces celestiales de un coro de vírgenes: 


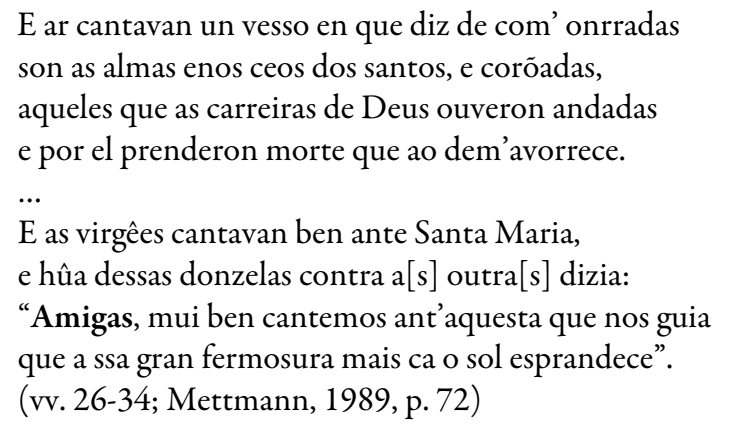

Otra información podría destacarse a fin de entender el uso de ciertos tópicos clásicos en la composición de la cantiga como, por ejemplo, el rastro de las laudes Britanniae en la primera estrofa, tal vez derivada del milagro versificado en la colección de Nigel de Canterbury. ${ }^{4}$

$\mathrm{Si}$ se comparan todas las fuentes hasta el texto en romance del siglo XIII, es decir, la cantiga 288 , se puede percibir una sutil transformación en el relato del milagro que tiene que ver con la forma en que se introduce el himno de Celio Sedulio en el contexto de la visión de San Dunstan. Mientras que en la Vita más antigua, su autor, $B$, incluyó los versos originales de Celio Sedulio, "Cantemus, socii, Domino" ("Cantemos, amigos, al Señor"), con una explícita mención al nombre del poeta, en los textos posteriores, en cambio, se lee "Cantemus, sociae, Domino", adaptándose así las palabras a las voces femeninas del coro de vírgenes.

La intervención de la Virgen con su discurso directo, inexistente en las versiones más antiguas de la vida de San Dunstan ( $B$, Eadmer, Osbern), así como en algunas de las posteriores, y que sí aparece en la versión de William de Malmesbury (la voz de la Virgen que invita a cantar alabanza a su Hijo), toma un importante lugar en la cantiga 296, cuando la voz de María se dirige a Dunstan. 


\begin{tabular}{|c|c|c|c|c|c|}
\hline$B$; Vita Dunstani & $\begin{array}{lr}\text { Osbern } & \text { de } \\
\text { Canterbury, } & \text { Vita } \\
\text { Dunstani } & \end{array}$ & $\begin{array}{l}\text { Eadmer de Canterbury, } \\
\text { Vita Dunstani }\end{array}$ & $\begin{array}{l}\text { William de Malmes bury, } \\
\text { De laudibus et miraculis } \\
\text { Sanctae Mariae, } 7\end{array}$ & $\begin{array}{l}\text { Vicente } \\
\text { Beauvais, } \\
\text { Speculum } \\
\text { historiale, } \\
\text { 113. } 1\end{array}$ & $\begin{array}{l}\text { Juan Gil de Zamora, } \\
\text { VII. } 14.9\end{array}$ \\
\hline $\begin{array}{l}\text { Himno citado con } \\
\text { mención de su } \\
\text { autor, Celio } \\
\text { Sedulio. }\end{array}$ & $\begin{array}{l}\text { Himno citado con } \\
\text { mención de su } \\
\text { autor, Celio } \\
\text { Sedulio. }\end{array}$ & $\begin{array}{l}\text { Himno citado, sin } \\
\text { mención del autor }\end{array}$ & $\begin{array}{l}\text { Himno citado, sin } \\
\text { mención del autor }\end{array}$ & $\begin{array}{l}\text { Himno citado, sin } \\
\text { mención del autor }\end{array}$ & $\begin{array}{l}\text { sin } \\
\text { utor }\end{array}$ \\
\hline $\begin{array}{l}\text { At ille [Dunstanus] } \\
\text { continuo per } \\
\text { quendam patuli } \\
\text { foraminis hiatum } \\
\text { inspiciens uidit } \\
\text { prelocutam } \\
\text { aecclesiam omni } \\
\text { esse ful gida luce } \\
\text { perfusam, et } \\
\text { uirgineas turmas } \\
\text { in choro gyranti } \\
\text { hymnum hunc } \\
\text { poetae Sedulii } \\
\text { cursitando } \\
\text { cantantes: } \\
\text { 'Cantemus, } \\
\text { socii, Domino' et } \\
\text { cetera. } \\
\text { 'Cantemus, } \\
\text { socii, Domino } \\
\text { cantemus } \\
\text { honorem: } \\
\text { Dulcis amor } \\
\text { Christi personet } \\
\text { ore pio' } \\
\text { et cetera. }\end{array}$ & $\begin{array}{l}\text { potuisti etiam } \\
\text { mellifluas ejus } \\
\text { [chori] uoces audire } \\
\text { (...): } \\
\text { Cantemus } \\
\text { domino, sociae, } \\
\text { cantemus } \\
\text { honorem. } \\
\text { Dulcis amor } \\
\text { Christi, personet } \\
\text { ore pio. ab aliis } \\
\text { Cumque ab hoc } \\
\text { virginibus } \\
\text { fuisset exceptum, } \\
\text { aliae qui sequuntur } \\
\text { versus } \\
\text { pronunciabant. } \\
\text { Primus ad ima ruit } \\
\text { magna de luce } \\
\text { superbus. } \\
\text { Sic homo cum } \\
\text { tumuit, primus ad } \\
\text { ima ruit. } \\
\text { Unius ob meritum } \\
\text { cuncti peiere } \\
\text { minores... }\end{array}$ & $\begin{array}{l}\text { Cantemus domino, } \\
\text { sociae, cantemus } \\
\text { honorem. } \\
\text { Dulcis amor Christi, } \\
\text { personet ore pio. } \\
\text { Quos versus chorus } \\
\text { virginum resumendo } \\
\text { percantans, praedictae } \\
\text { binae cantatrices, } \\
\text { binos qui sequuntur in } \\
\text { ordine versus } \\
\text { prosecutae sunt. } \\
\begin{array}{l}\text { Primus ad ima ruit } \\
\text { magna de luce } \\
\text { superbus. cum tumuit, } \\
\text { Sic homo cum } \\
\text { primus ad ima ruit }\end{array}\end{array}$ & 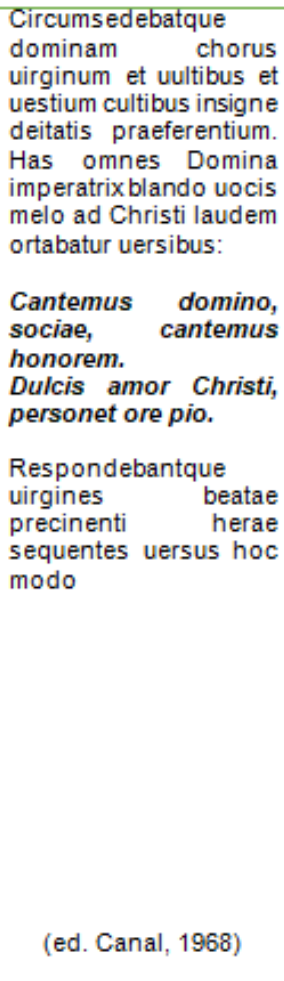 & $\begin{array}{l}\text { Cantemus } \\
\text { domino, sociae, } \\
\text { cantemus } \\
\text { honorem. } \\
\text { Dulcis amor } \\
\text { Christi, personet } \\
\text { ore pio. } \\
\text { Quos versus } \\
\text { virginum chorus } \\
\text { resumendo } \\
\text { percantauit, } \\
\text { Predictaeque } \\
\text { binae cantatrices, } \\
\text { binos qui } \\
\text { sequunturin } \\
\text { ordine versus } \\
\text { subsecutae sunt. } \\
\\
\text { Primus ad ima } \\
\text { ruit, etc. } \\
\text { Sicque donec vir } \\
\text { Dei in oratorium } \\
\text { perductus est, } \\
\text { virgineus chorus } \\
\text { binos, \& virgines } \\
\text { binae binos, iuxta } \\
\text { quod series hymni } \\
\text { se habere... }\end{array}$ & $\begin{array}{l}\text { Cantemus domino, } \\
\text { socie, cantemus } \\
\text { honorem, } \\
\text { Dulcis amor christi } \\
\text { personet ore pio. } \\
\text { Quos versus totus } \\
\text { alius choros } \\
\text { virginum } \\
\text { resumendo } \\
\text { percantat, } \\
\text { predicteque bine } \\
\text { cantatrices binos } \\
\text { qui sequuntur } \\
\text { versus subs equute } \\
\text { sunt: } \\
\text { Primus ad yma, ruit } \\
\text { magna de luce } \\
\text { superbus; } \\
\text { Sic homo, cum } \\
\text { tumuit, primus ad } \\
\text { yma ruit. } \\
\text { Sicque virum dei } \\
\text { cum tali } \\
\text { processione us que } \\
\text { ad ecclesiam } \\
\text { perduxerunt, } \\
\text { duabus semper } \\
\text { incipientibus, et } \\
\text { ceteris } \\
\text { respondentibus. } \\
\text { (ed. Fita, 1888) }\end{array}$ \\
\hline
\end{tabular}

Todas las piezas del cancionero alfonsí son poemas en alabanza a la Virgen, es decir, destinados al servicio de la Señora. No es azaroso que la cantiga 288 presente una traducción ligeramente retocada del verso original de Celio Sedulio, “Cantemus Domino”, que pasó a los textos latinos. No se trata, pues, de un error que podría hacer suponer un original "Cantemus Dominae". Tanto la voz de la Virgen en la cantiga 296 como la alabanza dirigida a ella en la 288 deben ser consideradas como evidencia de una "marianización” (fenómeno señalado oportunamente por Jaime Ferreiro Alemparte, 1971 y 1997) de los detalles del relato miracular original. Aunque pueda ser percibida como una diferencia muy leve, se trata, no obstante, de un procedimiento consistente a lo largo de todas las Cantigas de Santa María. El cambio de referencia de Cristo a su Madre no sorprende en absoluto en esta obra de Alfonso X en la que el lugar reservado a la Virgen es preeminente. También estos son rasgos que evidencian una "poética mariana” con vínculos mariológicos. Es llamativo que este fenómeno sea congruente con lo que venía aconteciendo en los mismos tropos litúrgicos ya desde el siglo XII en ámbito hispánico, tal como lo advierte Arturo Tello Ruiz-Pérez:

a partir de los siglos XII y XIII, la influencia creciente del culto mariano y la revalorizada importancia otorgada a la figura de la Virgen en la teología de este momento, encuentra su reflejo en los tropos del Sanctus en la misma medida que lo hace en otros tipos de tropos, himnos y secuencias. Así, términos como "virga Iesse floruit", "puerpera”, "stella", se convierten en habituales del lenguaje común de esta época. En esta dinámica, por ejemplo, la aposición "Mariae filius”, muy común especialmente en el este y habitualmente colocada entre las palabras "Benedictus" y "qui venit" del texto base, representa un caso muy revelador entre los tropos más tardíos.

(...) es muy habitual a partir de los siglos XII y XIII que el tema trinitario sea combinado o puesto en relación con el tema mariano. 
(...) María será uno de los temas centrales de los tropos del “Agnus Dei” en los manuscritos españoles. (Tello Ruiz-Pérez, 2006, pp. 397-398; 404; 497)

Como he indicado en el capítulo IV del estudio sobre la cultura monástica en las Cantigas de Santa María (Disalvo, 2013b), muchos himnos tradicionales son puestos en boca de algunos personajes destacados. En este tipo de cantigas, al igual que en la cantiga 180 antes tratada, es fundamental la presencia de la himnodia litúrgica, pero no explícita sino "escondida", como se demuestra en la cantiga 288. Este es uno de los resultados de la refinada tarea de cita, traducción y reelaboración de himnos litúrgicos que llevó a cabo el scriptorium de Alfonso X de maneras diversas.

En ese admirable equilibrio que la perspectiva alfonsí parece lograr entre lo laico y lo monástico en las Cantigas de Santa María confluye, además de los miracula marianos de tradición clerical latina, otro tipo de literatura entretejido en los versos de las cantigas narrativas y las cantigas de loor, textos que, si bien son producto de una novedosa creatividad poética en romance, dejan oír claramente las voces de un universo doctrinal teológico y mariológico y, especialmente, los ecos de la himnodia litúrgica.

\section{REFERENCIAS}

Anglès, H. (1931). El Codex musical de Las Huelgas (mùsica a veus dels segles XIII-XIV) [facsímil y transcripción]. Publicacions del Departament de Mùsica, Barcelona: Institut d'Estudis Catalans - Biblioteca de Catalunya.

Asensio Palacios, J. C. y Lorenzo Arribas, J. (Eds.) (2001). Códice de Las Huelgas. Madrid: Fundación Caja Madrid - Alpuerto.

Bell, N. (2004). El Códice Musical de las Huelgas: un estudio complementario del facsímil. Madrid: Testimonio.

Blume, C. y Dreves, G. M. (Eds.) (1886-1922). Analecta Hymnica Medii Ævi. 55 vols. (más índices), Reisland: Leipzig [reimpresión: Frankfurt am Main, 1961; 1978]; 1889, vol. II: Hymnarius Moissacensis. Das Hymnar der Abtei Moissac; 1898, vol. XXXI: Pia Dictamina. Reimgebete und Leselieder des Mittelalters; 1905, vol. XLVIII: Hymnographi Latini. Lateinische Hymnendichter des Mittelalters.

Clarke, D. C. (1955). Versification in Alfonso el Sabio's Cantigas. Hispanic Review, XXIII, 2, 83-98.

Canal, J. M. (Ed.) (1968). El libro "De laudibus et miraculis Sanctae Mariae" de Guillermo de Malmesbury, O.S.B. (c. 1143). Roma: Alma Roma.

Cantus: A Database for Latin Ecclesiastical Chant - Inventories of Chant Sources. Dirigido por D. Lacoste (2011-), T. Bailey (1997-2010) y R. Steiner (1987-1996). http://cantus.uwaterloo.ca/ [Hesbert, R. J. (Ed.) (1963-1979). Corpus Antiphonalium Officii. 6 vol., Roma : Herder.]

Crane, T. F. (Dir.) (1925). Liber de Miraculis Sanctae Dei Genitricis Mariae. Published at Vienna in 1731 by Bernard Pez, O.S.B. Cornell University Studies in Romance Language and Literature 1, Ithaca - London - Oxford: Cornell University.

Curtius, E. R. (1955). Literatura Europea y Edad Media Latina. M. Frenk y A. Alatorre (Trads.), México: Fondo de Cultura Económica.

Disalvo, S. (2010). Hortus Deliciarum et Flos Spineti: el jardín y las flores de María, de la poesía litúrgica a la lírica hispánica medieval. Revista do Centro de Estudos Portugueses, 30(44), CESP-FALE (UFMG), 131-151.

Disalvo, S. (2012a). Adam vetus tandem laetus novum promat canticum: Adán de San Víctor y la novedad del canto victorino en la lírica mariana medieval. En L. Galán, G. Chicote et al. (Eds.), Actas de las V Jornadas de Estudios Clásicos y Medievales "Diálogos Culturales": "Juventud y vejez en la Antigüedad y el Medioevo. Diálogo entre culturas: de lo antiguo a lo contemporáneo". La Plata: IdIHCS / AADEC. Recuperado de http://sedici.unlp.edu .ar/bitstream/handle/10915/33326/Documento_completo__.pdf?sequence=1\&isAllowed=y

Disalvo, S. (2012b). El planctus de la Virgen en la Península Ibérica, desde el Quis dabit hasta las Cantigas de Santa María. En M. M. Rodríguez Temperley, S. Disalvo, V. Bonatto, F. Bonfiglio, D. Chazarreta, E. di Croce, E. Hafter, G. Rodas, M. P. Salerno (Eds.), "El Hispanismo ante el Bicentenario". Actas del IX Congreso de la Asociación 
Argentina de Hispanistas, La Plata: IdIHCS / AAH. Recuperado de http://ixcah.fahce.unlp.edu.ar/actas/disal vo-santiago.pdf/view

Disalvo, S. (2013a). Los cantos marianos del Códice de Las Huelgas de Burgos: tradición e innovación en la lírica monacal hispánica. En G. Coronado-Schwindt, V. Gastaldi, G. Marrón y G. Rodríguez (Eds.), Palimpsestos: Escrituras y reescrituras de las culturas Antigua y Medieval (pp. 95-103). Bahía Blanca: EdiUNS.

Disalvo, S. (2013b). Los monjes de la Virgen: representación y reelaboración de la cultura monacal en las Cantigas de Santa Maria de Alfonso X. Newark: Juan de la Cuesta.

Disalvo, S. (2013c). Los VII goyos de la Virgen en las Cantigas de Santa María y la tradición de los gaudia en la poesía medieval latina y vernácula. Revista do Centro de Estudos Portugueses, 32(47), CESP-FALE (UFMG), 39-66.

Disalvo, S. (2014). Translatio materiae: adopción de formas y géneros latinos en las colecciones hispánicas de milagros marianos. Stylos, 23, 139-157.

Disalvo, S. (2015). El gozo del Paraíso en dísticos elegíacos: notas sobre algunos milagros marianos de Nigel de Canterbury. Auster. Revista del Centro de Estudios Latinos, 20, 83-96.

Donavin, G. (2012). Scribit Mater: Mary and the Language Arts in the Literature of Medieval England. Washington DC: The Catholic University of America Press.

Donavin, G. (2019). The Virgin Mary as Lady Grammar in the Medieval West, Traditio, 74, 279-305.

Ferreiro Alemparte, J. (1971). Fuentes germánicas en las Cantigas de Santa María de Alfonso X el Sabio. Grial, 31, 31-62.

Ferreiro Alemparte, J. (1997). Fuentes y contexto histórico de algunos milagros de Cesario de Heisterbach poéticamente marianizados y musicalizados en las Cantigas de Santa María, de Alfonso X el Sabio, y su relación con el monasterio de Gumiel de Izán. Museo de Pontevedra, 51, 527-539.

Fidalgo, E. (2003). As Cantigas de Loor de Santa Maria (edición e comentario). Santiago de Compostela: Centro Ramón Piñeiro - Xunta de Galicia.

Fita, F. (1885). Variantes de tres leyendas por Gil de Zamora. Boletin de la Real Academia de la Historia, 6, 418-429.

Fita, F. (1888). San Dunstán, arzobispo de Cantorbery, en una cantiga del rey D. Alfonso el Sabio. Boletin de la Real Academia de la Historia, 12, 244-248.

Gambero, L. (2000). Maria nel pensiero dei teologi latini medievali. Milano: San Paolo.

Mettmann, W. (1979). Zum Stil der Cantigas de Santa Maria (I). M. Höfler et al. (Eds.), Kurt Baldinger zum 60. Geburtstag (pp. 304-313). Tübingen: Niemeyer.

Mettmann, W. (Ed.), 1986-1989. Alfonso X, el Sabio. Cantigas de Santa María, Madrid: Castalia, t. I (1986), t. II (1988), t. III (1989).

Migne, J. P. (Ed.) (1844-55). Augustinus Hiponensis, In Psalmum 148 enarratio. Sermo ad plebem, 17. En Patrologia Latina. Paris, vol. 36, col. 67-1026; vol. 37, col. 1033-1966.

Muir, B. J. y Turner, A. J. (Eds.) (2006). Eadmer of Canterbury. Lives and Miracles of Saints Oda, Dunstan, and Oswald. Oxford: University Press.

Nascimento, A. A. (1979). Um Mariale alcobacense. Didaskalia, IX, 339-411. Recuperado de http://www.cervantes virtual.com/FichaObra.html?portal $=0 \&$ Ref $=29565$

Noell, B. (1999). Marian Lyric in the Cistercian Monastery during the High Middle Ages. Comitatus. A Journal of Medieval and Renaissance Studies, 30(1), 37-62. Recuperado de https://escholarship.org/uc/item/663723dp

Rossi, G. y Disalvo, S. (2008). La cantiga III de las Fiestas de Santa Maria ('Tod' aqueste mund' a loar deveria') y la secuencia Novis cedunt vetera: filiaciones textuales y musicales entre las Cantigas de Santa María y el Códice de Las Huelgas. Olivar. Revista de Literatura y Cultura Españolas, 9(11), 13-26. Recuperado de https://www.oliva r.fahce.unlp.edu.ar/article/view/OLIv09n11a01

Santi, F. (2004). Mariologia e cosmologia nei secoli XI e XII. Alcuni esempi. En C. Piastra y F. Santi (Eds.), Figure poetiche e figure teologiche nella mariología dei secoli XI e XII. Firenze: SISMEL-Edizioni del Galluzzo.

Stubbs, W. (ed.) (1874). Osbern of Canterbury. Memorials of St Dunstan, archbishop of Canterbury. Rolls Series 63, London. 
Szövérffy, J. (1983). Psallat Chorus Caelestium. Religious Lyrics of the Middle Ages (Hymnological Studies and Collected Essays). Berlin: Classical Folia Editions.

Tello Ruiz-Pérez, A. (2006). Transferencias del canto medieval: los tropos del "ordinarium missae" en los manuscritos españoles (tesis doctoral). Madrid: Universidad Complutense.

Twomey, L. (2008). The Serpent and the Rose: The Immaculate Conception and Hispanic Poetry in the Late Medieval Period. Leiden: Brill.

Vandrey, P. L. (1977). How Different is Alfonso's Canticle 421? Journal of Hispanic Philology, 1, 147-149.

Vicente de Beauvais / Vincentius Bellovacensis (1624). Speculum historiale. Bibliotheca mundi Vincentii Burgundi ex ordine Praedicatorum vener. Episcopi Bellovacensis. Speculum quadruplex, naturale, doctrinale, morale, historiale..., t. IV, Theologorum Benedictinorum Collegii Vedastini (Academia Duacensi), Duaci (Douai): Balthazar Bellere.

Wellner, F. (Ed.) (1955). Adam S. Victoris (Adam von Sankt Victor), Sämtliche Sequenzen. München.

Winterbottom, M. y Lapidge, M. (Eds.) (2011). The Early Lives of St Dunstan. Oxford Medieval Texts.

Ziolkowski, J. (Ed.) (1986). Nigel of Canterbury (Nigellus Wireker), Miracles of the Virgin Mary, in Verse / Miracula Sancte Dei Genitricis Virginis Marie, Versifice. Toronto Medieval Latin Texts 17, Toronto: Institute of Medieval Studies.

\section{Notas}

1 Los primeros esbozos de este estudio fueron pronunciados como una comunicación, "Music as Heavenly Pleasure: the Vision of Saint Dunstan in Medieval Marian Miracles" (International Medieval Congress, University of Leeds, 1 al 4 de julio de 2013) y una conferencia en el curso de verano Afonso X, o Sabio: cronista e protagonista do seu tempo, organizado por la doctora Elvira Fidalgo (Universidade de Santiago de Compostela, 26 al 28 junio de 2017).

2 "Hymnus scitis quid est? Cantus est cum laude Dei. Si laudas Deum, et non cantas, non dicis hymnum: si cantas, et non laudas Deum, non dicis hymnum: si laudas aliud quod non pertinet ad laudem Dei, etsi cantando laudes, non dicis hymnum. Hymnus ergo tria ista habet, et cantum, et laudem, et Dei. Laus ergo Dei in cantico, hymnus dicitur. "(San Agustín de Hipona, InPsalmum 148 enarratio. Sermo ad plebem).

3 Como posible fuente de esta cantiga, el estudio de Fidel Fita ya señalaba el Chronicon de Hélinand de Froidmont (en el cual también se basa el Speculum historiale de Vicente de Beauvais). Fita también menciona la Vita de Osbern: "En esta biografía contemporánea de San Dunstán [i.e. la de Osbern] halla también su explicación y primer origen la Cantiga XXIII, que se intitula: Esta e como Santa María acrecentóu o vynno no tonel, por amor da bona dona de Bretanna. La noble matrona, de regia estirpe, es la viuda Santa Elfleda; el rey, en cuyo obsequio se obró el milagro, es Ethelstán ó Aldestán, el que hizo traducir la Biblia en lengua sajona; y la escena finalmente pasó en Glastonbury (Somerset), de cuya célebre abadía era monje á la sazón y abad San Dunstán, antes de ser elevado en el año 958 á las cátedras episcopales de Worcester y de Londres, y el año siguiente á la metropolitana de Cantorbery” (Fita, 1888, p. 248).

4 En el primer libro de sus Miracula Sancte Dei Genitricis Virginis Marie, Versifice, Nigel de Canterbury incluye el milagro "De Sancto Dunstano" (segundo en el orden), adornado con una rica retórica y varios tópicos poéticos. Por un lado, el tópico del puer senex, empleado para describir la figura del joven San Dunstan; por otro, la alabanza de la propia patria, o laudes Britanniae. Nigel toma el modelo de este tópico de la Historia Ecclesiastica Gentis Anglorum de San Beda el Venerable (cfr. Disalvo, 2015). 